\title{
Physical measurement methods for on-chip cell analysis
}

\author{
Michael J. Vellekoop \\ University of Bremen, Institute for MicroSensors, -Actuators and -Systems (IMSAS), MCB, \\ Otto-Hahn-Allee, NW1, D-28359 Bremen, Germany \\ mvellekoop@imsas.uni-bremen.de
}

\section{Summary}

The analysis and sorting of biological cells in microfluidic chips has been one of the fastest growing sensor-research topics in the past few years. The characteristic scale of microfluidics devices (channel diameter from a few to some tens of micrometers) fits very well to the typical size of cells which makes them a very useful platform for the analysis and handling of cells. In addition, the integration of sensors and actuators into such microfluidics chips is a matured technology, allowing the design of numerous elements for the diagnosis of cells.

Not only cell cultures are studied on a chip but also single cells, which yields more specific information, for example on the initiation of diseases. In addition to chemical analysis methods (e.g. ion selective electrodes or electrochemistry) also physical analysis methods can be applied to retrieve information from cells. A driving force to apply physical sensors is the potential of label-free analysis which makes the measurement faster and cheaper.

In this contribution an attempt is made to give an overview of current physical measurement and actuating principles for the on-chip analysis of cells.

\section{Physical effects for cell analysis}

In the past decade, numerous sensing and actuating elements have been invented, investigated, and developed to retrieve information from cells in a small chip. Sensors and actuators that make use of physical effects are based on optical, electrical, magnetic, thermal or mechanical measurement principles.

The optical domain has proven extremely useful for the analysis of cells. Optical elements can be integrated on the chip and light can be coupled in and out relatively easy with optical fibers. Well-known are fluorescence, luminescence, and light absorption. In on-chip flowcytometry light absorbed or scattered by flowing single cells is examined. Also in droplet microfluidics where cells are located in very small droplets that act as a well-defined reaction chamber, optical methods are applied [e.g. 1]. Recently, a novel method to determine the change of refraction index of very small liquid volumes on a chip, for example caused by a chemical reaction, was published [2]. Microfluidic chips also allow accurate spectrometric analysis of cells; infrared [e.g. 3] and Raman spectroscopy [e.g. 4] show highly interesting results. Of course, these spectrometric analysis systems cannot be called a sensor but there are specific applications for which a sensor system is designed and built on the basis of spectrometer research results. An example is the detection of cancer cells in biopsies on the basis of the ratio of infrared light absorption by symmetric and anti-symmetric $\mathrm{CH}_{2}$ in the cell membrane [5]. It appears that the occurrence of cancer in cells causes a shift of the concentration of anti-symmetric stretch $\mathrm{CH}_{2}$ to symmetric stretch $\mathrm{CH}_{2}$. By determining the ratio of the two infrared absorption lines, the measurement is independent of the amount of cells that are in the sample and also fluctuations of laser intensity are being compensated for. The next step is to apply this method for living cells.

Holography has been applied to make three dimensional images of (flowing) cells in microfluidic chips. Although also not a sensor technique, the method yields - in addition to cell size - fascinating information on the cell's nucleus, membrane, and cytoplasm [e.g. 6]. 
Amongst electrical methods to analyze cells the best known are impedance spectroscopy [7], and capacitance measurements. A highly interesting electronics-based method for the analysis of cells in vitro, are CMOS based microelectrode arrays. The cells are cultured directly on the chips. With the arrays an interface to electrogenic cells can be established which allows monitoring of the electrical activity of these cells, including the electrical activity between cells [8]. Both electrical stimulations and recordings are possible with these arrays.

An electrical effect that is used as an actuator for the separation of cells is dielectrophoresis [9]. In a non-uniform electrical field in a micro flow channel mechanical forces can be applied to living single cells. Different cell types experience different forces or even forces in opposite directions. This allows the separation of one cell type from the other in a system without moving elements. The dielectrophoretic effect can be realized by introducing electrodes in the flow channel that are designed to create a non-uniform electrical field. This method is now evolving into a robust system for sorting out specific and small amounts of cells from complex cell-containing fluids [10]. An example of such a complex fluid is blood [11].

To determine the mechanical properties of cells one of the first tools applied was atomic force microscopy (AFM). The investigation of the changing mechanical properties of the membrane of cancer cells applying AFM has yielded promising results [12]. In a recent publication a few other mechanical analysis methods that can be applied in a microfluidic chip have been discussed and are referred to as "mechanical biomarkers" [13]. Examples given are cell deformability and "hydrodynamic stretching". For both methods microfluidic elements have been designed.

The heat production in cells (thermogenesis) is being investigated by applying highly sensitive calorimetric elements. It should give information on the cells metabolism and can be used to investigate influence of different environmental parameters on the cell's metabolism [14]. Investigations are ongoing to apply fast differential scanning calorimetry (FDSC) for protein analysis [15].

In the magnetic domain the application of magnetic beads that bind to specific cells which can then simply be sorted out with a magnet is a proven illustration of the use of magnetics for cell analysis [16]. Several types of commercial magnetic beads for cell separation are on the market, e.g. Dynabeads Technology [17]

It can be concluded that its suitability for label-free and fast analysis makes physical measurement and actuation methods very attractive for the investigation of biological cells. Because of the relative ease of integration in microfluidic devices, the concept also shows good prospects for commercial products.

\section{Acknowledgements}

Financial support of the European Marie Curie Initial Training Network EngCaBra, project no. PITN-GA-2010-264417 is gratefully acknowledged. 


\section{References}

1 Brouzes E, Medkova M, Savenelli N, Marran D, Twardowski M, Hutchison JB, Rothberg JM, Link DR, Perrimon $\mathrm{N}$, Samuels ML, "Droplet microfluidic technology for single-cell high-throughput screening", PNAS August 25, 2009 vol. 106 no. 34 14195-14200, DOI: 10.1073/pnas.0903542106.

2 Weber E, Vellekoop MJ, "Optofluidic micro-sensors for the determination of liquid concentrations", Lab Chip. 2012 Aug 20;12(19):3754-9, DOI:10.1039/C2LC40616K.

3 Mourant JR, Rowena RR, Johnson TM, Carpenter S, Short KW, Yamada YR, Freyer JP, “Methods for measuring the infrared spectra of biological cells", Phys. Med. Biol. 48 (2003) 243-257.

4 Notingher I, "Raman Spectroscopy Cell-based Biosensors", Sensors 2007, 7, 1343-1358.

5 van den Driesche S, Witarski W, Pastorekova S, Breiteneder H, Hafner C, Vellekoop MJ, "A label-free indicator for tumor cells based on the CH2-stretch ratio", Analyst, 11 (2011), 136; pp. 2397 - 2402, DOI: 10.1039/c1an15076f.

6 Kemper B, von Bally G, "Digital holographic microscopy for live cell applications and technical inspection", Applied Optics, Vol. 47, No. 4, 2008, pp. A52-61.

7 Malleo D, Nevill JT, Lee LP, Morgan H, "Continuous differential impedance spectroscopy of single cells", Microfluid Nanofluid, DOI: 10.1007/s10404-009-0534-2.

8 A. Hierlemann, U. Frey, S. Hafizovic, F. Heer, "Growing Cells atop Microelectronic Chips: Interfacing Electrogenic Cells in Vitro with CMOS-based Microelectrode Arrays", Proceedings of the IEEE, 2011, Vol. 99, No. 2, pp. 252-284.

9 Jones TB, Electromechanics of particles (Cambridge University Press, Cambridge, 1995).

10 van den Driesche S, Rao V, Puchberger-Enengl D, Witarski W, Vellekoop MJ, "Continuous Cell from cell separation by traveling wave dielectrophoresis", Sens. Actuators B 2011, doi:10.1016/j.snb.2011.01.012.

$11 \mathrm{Han} \mathrm{KH}$, Frazier AB, "Lateral driven continuous dielectrophoretic microseparators for blood cells suspended in a highly conductive medium", Lab Chip, 2008, vol. 8, pp. 1079-1086.

12 Lin C, Yin T, Lin Y, Huang C, Lin T, Chen T, Lin J, Wu H, Chang H: Study on Mechanical Properties of Thrombomodulin Transfected Cancer Cell by Atomic Force Microscopy J Med Biol Eng, 2010; 30 (5): 313 320.

13 Mao X, T. Huang, "Exploiting mechanical biomarkers in microfluidics", Lab Chip, 2012, 12, 4006-4009.

14 Inomata N, Toda M, Sato M, Ishijima A, Ono T, "Pico calorimeter for detection of heat produced in an individual brown fat cell”, Appl. Phys. Lett. 100, 154104 (2012); doi: 10.1063/1.3701720.

15 Splinter R, van Herwaarden AW, lervolino E, Vanden Poel G, Istrate D, Sarro PM, “Analyzing protein denaturation using Fast Differential Scanning Calorimetry", Procedia Engineering, 47 (2012) 140-143.

16 Wang H, Mahdavi A, Tirrell DA, Hajimiri A, “A magnetic cell-based sensor", Lab Chip, 2012, 12, 4465-4471, DOI: $10.1039 / c 21 c 40392 \mathrm{~g}$.

17 www.invitrogen.com/dynabeads 